\title{
Business Unit Strategy, Managerial Characteristics, and Business Unit Effectiveness at Strategy Implementation ${ }^{1}$
}

\author{
ANIL K. GUPTA \\ Boston University \\ V. GOVINDARAJAN \\ Ohio State University
}

Data from 58 strategic business units ( $S B U$ s) reveal that greater marketing/sales experience, greater willingness to take risk, and greater tolerance for ambiguity on the part of the $S B U$ general manager contribute to effectiveness in the case of "build" SBUs but hamper it in the case of "harvest" SBUs.

Despite the widespread acceptance of strategy's role in mediating an organization's interaction with its environment (Andrews, 1971; Ansoff, 1965; Chandler, 1962; Child, 1972; Miles \& Snow, 1978), the scope of research on strategy "implementation" has remained quite narrow. Following Chandler (1962), the concern has been predominantly with how a firm's organizational structure and control system are, or might be, related to the degree and nature of its product and geographic diversification (Fouraker \& Stopford, 1968; Grinyer, Al-Bazzaz, \& Yasai-Ardekani, 1980; Rumelt, 1974; Scott, 1973; Vancil, 1980). However; strategy formulation and implementation take place not just at the level of the diversified firm as a whole, but also at the level of the divisions/strategic business units (SBUs) comprising the firm (Hambrick, 1980; Hofer \& Schendel, 1978). In such a context, the near absence of empirical studies on strategy implementation at the SBU level presents a significant research opportunity.

\footnotetext{
${ }^{1}$ Both authors contributed equally. They are grateful to Lloyd Baird, Max Bazerman, Arvind Bhambri, W. W. Cooper, Jesse Dillard, Kenneth Hatten, Kenneth Merchant, James Post, Charles Snow, Ray Stephens, Richard Vancil and two anonymous reviewers for valuable comments on earlier drafts of this paper. Funding support for the research on which it is based was provided by the Graduate School, Boston University; the Division of Research, Graduate School of Business Administration, Harvard University; and the College of Administrative Science, Ohio State University. Portions of this paper were presented at and published in the proceedings of the 42nd annual meeting of the Academy of Management, New York, 1982.
} 
On a prima facie basis, the effectiveness of strategy implementation at the SBU level can be expected to depend on: (a) the characteristics of the SBU's general manager (Galbraith \& Nathanson, 1978; Kerr, 1982); (b) the SBU's internal organization (Lawrence \& Lorsch, 1967; Miles \& Snow, 1978); and (c) the nature of corporate control over the SBU (Bower, 1970; Vancil, 1980). Focusing exclusively on the first of these three factors, this paper presents an exploratory empirical study of the effects of linking managerial characteristics to SBU strategy on SBU effectiveness at strategy implementation. SBU strategy is operationalized in terms of the strategic mission. The managerial characteristics studied are: length of prior experience in the marketing/sales function, willingness to take risk, and tolerance for ambiguity. Effectiveness at strategy implementation is assessed perceptually through a multivariate approach utilizing criterion weights.

\section{Theoretical Background}

\section{Business Unit Strategy}

Strategic mission/portfolio strategy (Henderson, 1970; Hofer \& Schendel, 1978), competitive posture (Porter, 1980), and the extent and nature of linkages with other SBUs within the same corporation (Rumelt, 1974; Vancil, 1980) constitute some of the most critical strategic issues at the SBU level. Although all of these strategic dimensions have the potential to influence the utility of various managerial characteristics, this study focuses only on the implications of variations in strategic mission.

By definition, strategic mission (or portfolio strategy) signifies the nature of the SBU's intended trade-offs between market share growth and short term earnings/cash flow maximization (Abell \& Hammond, 1979; Henderson, 1970). Similar to Larreche and Srinivasan (1982), the present authors view potential strategic missions as spanning a continuous spectrum. At one end of the spectrum are SBUs whose mission is to increase market share and competitive position even though short term earnings and cash flow generation may be low or negative; these SBUs are likely to have "weak competitive positions" in relatively "attractive industries." At the other end are SBUs whose mission is either divestiture or the maximization of short term earnings and cash flow even though a slippage in the SBU's market share and competitive position may ensue; these SBUs are likely to have "strong competitive positions" in relatively "unattractive industries." Although most strategy researchers (Buzzell \& Wiersema, 1981; Hofer \& Schendel, 1978; MacMillan, 1982; Rothschild, 1976) have tended to operationalize strategic mission as a nominal variable, a closer examination of the typologies developed indicates that these nominal approaches are essentially consistent with the continuous approach being taken in this study. For instance, the six categories of Hofer and Schendel (1978)-share increasing strategies, growth strategies, profit strategies, market concentration and asset reduction strategies, turnaround strategies, and liquidation 
or divestiture strategies - and the eight categories of MacMillan (1982)-aggressive build, gradual build, selective build, aggressive maintain, selective maintain, competitive harasser, prove viability, and divest-all reflect a more or less steady transition from a "pure build" strategy at one end to a "pure harvest"' or "divest" strategy at the other. Because this study focuses on strategy implementation for ongoing businesses only, its focus is only on the continuum from "pure build" to "pure harvest," and it does not deal with the implications of a "divest" strategy.

\section{Strategy Implementation-A Contingency Perspective}

The study's conceptual roots lie in the idea that effectiveness at realizing intended strategies depends significantly on the existence of a match between strategy and organization. Originally advanced by Chandler (1962), such a contingency perspective on organization since has been reinforced/extended by Fouraker and Stopford (1968), Lawrence and Lorsch (1967), Lorsch and Allen (1973), Rumelt (1974), Scott (1973); Thompson (1967), and Vancil (1980). Although none of these studies has looked at the relationship between strategy and organization at the SBU level, the consistency with which systematic relationships between strategy and organization have been discovered at the overall firm level would lead one to expect the existence of a similar relationship at the SBU level, too. Given Galbraith and Nathanson's (1978) comprehensive review of this research, this section will focus on only one study with a more direct bearing on the subject matter at hand.

Looking closely at how, within diversified firms, resource allocation decisions are actually made, Bower (1970) found that the nature of capital investment projects initiated by business unit management was strongly influenced by the "structural context" established by corporate (i.e., parent corporation level) management. Because the choice of individuals who act as general managers of the business units is a key component of the intracorporate structural context, Bower's study implies that individual characteristics of these general managers significantly influence SBU-level strategy implementation. However, Bower did not look at the precise nature of the relationship between business unit strategy, managerial characteristics, and effectiveness at strategy implementation. This is what the present study aims to do.

\section{Contingency and Managerial Characteristics}

Further, though indirect, support for the expectation of a contingency relationship between strategy and managerial characteristics comes from literature dealing with the effects of a fit between individual personality and job. Although undertaken in diverse organizational contexts, several empirical studies (Griffin, 1980; Lorsch \& Morse, 1974; O'Reilly, 1977) have discovered that congruence between individual personality and task 
characteristics is associated with greater effectiveness as well as greater job satisfaction. Conceptually, Fiedler (1965) and Lawler (1974) also have argued for the need to match managerial characteristics with job requirements. Although none of these studies has examined the particular case of general managers and the task characteristics dictated by business unit strategies, the general similarity in the logic behind and the empirical support for these findings is noteworthy.

It also is relevant to note that strategy consultants such as Arthur D. Little Inc. (Wright, 1974), Bakkenist Management Consultants, Holland (Wissema, Van Der Pol, \& Messer, 1980), the Boston Consulting Group ("Wanted: A manager," 1980), and others have argued consistently that managers in charge of "build" businesses need to be more entrepreneurial as compared to those in charge of "harvest" businesses. In commenting on these arguments, Galbraith and Nathanson capture well the raison d'être for the present research:

[An] approach to the people dimension. . .taken by consulting firms selling strategy-making packages to multi-divisional firms... is to match the product division manager with particular stages on the product life cycle... These ideas are very much like Chandler's concepts. However, appealing these ideas are, they have yet to be tested $(1978$, p. 88).

\section{Hypotheses}

\section{Experience Background}

Snow and Hrebiniak's (1980) study on linkages between strategy and distinctive competence indicated that although organizational strengths in general and financial management were important for all strategies, the importance of strengths in basic engineering, research and development, production, and applied engineering varied from one strategy type to another. More recently, Hitt, Ireland, and Palia (1982) also provided similar evidence in support of a systematic relationship between organizational strategy and the importance of various functions. The basic explanation for these findings has been that different strategies require different skills for successful implementation. The focus of both of these studies has been on the overall "grand strategy" of the corporation rather than on the strategy of intracorporate business units, and their conceptualizations of strategy are different from each other as well as from those of the present authors. Their findings, however, do lend support to the expectation that the functional background of the SBU general manager (GM) would be related to SBU strategy.

A build strategy signifies an intent to increase market share. Because the total market share of all firms in an industry would always be 100 percent, such a strategy can be implemented only through the establishment of some marketplace superiority over competitors. At a minimum, this would require managerial orientation towards, and competence at monitoring and analysis of, external industry characteristics such as consumer needs and competitor strategies. In contrast, a harvest strategy signifies an intent to 
maximize short term profit and cash flow rather than to increase market share. For businesses with such a strategy, skills at boosting the internal efficiency of operations rather than at external industry analysis would seem to be more important. Taking these arguments into account, the straightforward assumption that marketing/sales experience contributes positively to the development of skills at external industry analysis now yields the following hypothesis:

Hypothesis 1: Experience in marketing/sales on the part of the GM will make a greater contribution to effectiveness at strategy implementation in the case of SBUs at the "build" end of the strategy spectrum than in the case of SBUs at the "harvest" end.

This exclusive focus on managerial experience in only one function, marketing/sales, does not imply an expectation that experience in other functional areas (such as manufacturing and research and development) has no impact on SBU effectiveness at strategy implementation. Nonetheless, it does reflect the authors' expectation that strategic factors other than SBU. "mission"-for instance, "competitive posture" in the sense of Porter (1980) - would have a much stronger and more direct impact on the utility of managerial experience in these other functional areas.

\section{Willingness to Take Risk and Tolerance for Ambiguity}

Hypotheses relating the SBU general manager's willingness to take risk and his/her tolerance for ambiguity to SBU strategy and effectiveness are developed on the premises (1) that managers in charge of SBUs with build strategies face a more uncertain task environment than do managers in charge of SBUs with harvest strategies and (2) that strategy implementation under conditions of greater uncertainty requires greater willingness to take risk and greater tolerance for ambiguity.

There are two arguments in support of the expectations of a positive association between business unit strategy and environmental uncertainty. First, by definition, a build strategy signifies a desire to increase market share, whereas a harvest strategy signifies, at best, an indifference towards it. Because the total market share of all firms in an industry would always be 100 percent, making the battle for market share a zero-sum game, it is clear that a build strategy pits an SBU into greater conflict with its competitors than does a harvest strategy. As Pfeffer and Salancik (1978) have argued, the greater the degree of conflict between an organization and actors in its external environment, the greater is the uncertainty confronted by it. Second, from the preceding discussion it also is clear that the decision to increase market share makes a build manager, relative to a harvest manager, more dependent on the decisions and actions of customers and competitors. To increase market share, however, it is not sufficient just to increase the demand for one's products; one also must increase the input of resources and the volume of production by corresponding amounts. Thus, even on the input side-that is, with respect to sources of raw material, 
labor, capital, and so on-a build manager faces greater external dependencies than does a harvest manager. As Pfeffer and Salancik (1978) as well as Thompson (1967) have argued, given a nondeterministic world, the greater the external dependencies facing an organization, the greater the uncertainty confronted by it. Thus, build SBUs can be expected to face more uncertain task environments relative to harvest SBUs.

As decision theory points out, with uncertainty goes risk. True, objectivists (Knight, 1921) have argued that decision making under uncertainty is different from making risky decisions. According to this view, the term risk can be associated only with situations in which the objective probability distribution of various possible outcomes is known; all other situations are to be treated as decision making under uncertainty. Contemporary decision theory (Luce \& Raiffa, 1957) argues, however, that a subjective probability distribution always can be constructed. Thus, as long as the possibility of more than one outcome exists, the decision making situation must be regarded as involving both uncertainty and risk. Alternatively stated, to be effective, managers in charge of more uncertain task situations should be willing to take greater risks. A parallel argument for the expectation of similar linkages among tolerance for ambiguity, environmental uncertainty, and effectiveness has been made by Lorsch and Morse (1974). These arguments lead to the following hypotheses regarding linkages among SBU strategy, managerial risk-attitude, tolerance for ambiguity, and SBU effectiveness:

Hypothesis 2: Willingness to take risk on the part of the GM will make a greater contribution to effectiveness at strategy implementation in the case of SBUs at the "build" end of the strategy spectrum than in the case of SBUs at the "harvest" end.

Hypothesis 3: Tolerance for ambiguity on the part of the GM will make a greater contribution to effectiveness at strategy implementation in the case of SBUs at the "build" end of the strategy spectrum than in the case of SBUs at the "harvest" end.

\section{Method}

\section{The Sample}

Data were collected from the general managers of 58 SBUs within 8 Fortune 500 diversified firms headquartered in Massachusetts, Connecticut, and the state of New York. The need to obtain access and the constraints of time and funding prevented the use of a random sample either from the entire Fortune 500 or from the entire subset of firms headquartered in the Northeast. Given, however, their size range (in 1980 sales, from about $\$ 500$ million to about $\$ 10$ billion) and the diversity of industries in which they operate (consumer products, industrial machinery, chemicals, electronic components, electronic equipment, etc.), there is no prima facie reason to expect any systematic bias in the findings from business units within these firms. 
Within each firm, the head of corporate planning as well as one or more senior line executives (usually a group vice president) were interviewed. As part of the research project, these executives agreed to send a questionnaire instrument to four or more SBU general managers within their firm, making sure that a mix of strategically diverse businesses would be covered. A cover letter to the questionnaire guaranteed the respondents that none of their responses would be disclosed to anybody and that only summary data from the total responses from several business unit heads in several firms would be published. A preaddressed stamped envelope also was enclosed with each questionnaire to enable the respondents to mail these back without the risk even of perusal by secretarial staff. Of the 70 questionnaires distributed by corporate level executives, 58 usable responses were received. Because of the high response rate, no tests for nonresponse bias were considered necessary.

\section{Measurements}

Intended SBU Strategy. Preliminary interviews with four SBU managers in one firm had revealed, as expected, that although the terms build, hold, harvest, and divest can be applied to the business unit as a whole, each SBU usually consists of several closely related products/product lines. As such, strategy for the SBU as a whole needed to be regarded as an aggregate of the strategies of its products. Based on this logic, the following question was posed to the SBU manager:

\footnotetext{
Given below are descriptions of several alternative strategies. Depending upon the context, each of these descriptions may represent the strategy for all or only a fraction or none of a business unit's products. Please indicate below what percentage of your business unit's current total sales is accounted for by products represented by each of these descriptions. Your answers should total $100 \%$.

-Increase sales and market share, be willing to accept low returns on investment in the short-to-medium term, if necessary

-Maintain market share and obtain reasonable return on investment

-Maximize profitability and cash flow in the short-to-medium term, be will-

ing to sacrifice market share if necessary

- Prepare for sale or liquidation

- None of the above (please specify)

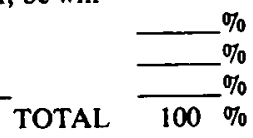

In descending order, these strategy descriptions were intended to signify the following intended strategies: build, hold, harvest, divest, and other. All respondents entered 0 percent under "none of the above." Only 12 of the 58 respondents entered anything other than zero for the divest strategy; and, even here, the percentage ranged from 2 percent to only 13 percent. Thus, at the level of the SBU as a whole, all 58 subject SBUs can be characterized as having strategies that fall somewhere along the continuum from "pure build" to "pure harvest."

The measure for strategy was derived as follows. A value of +1 was attached to a build strategy, a 0 to a hold strategy, a -1 to a harvest strategy, and $\mathrm{a}-2$ to a divest strategy. The percentage breakdown provided by the SBU manager then was used to arrive at a weighted average strategy index. 


\section{Table 1 \\ Summary Statistics on and \\ Zero-Order Correlation Coefficients Among \\ All Variables under Study}

\begin{tabular}{|c|c|c|c|c|c|c|c|c|}
\hline \multirow[b]{2}{*}{ Variable } & \multirow[b]{2}{*}{ Minimum } & \multirow[b]{2}{*}{ Maximum } & \multirow[b]{2}{*}{ Mean } & \multirow[b]{2}{*}{ S.D. } & \multicolumn{4}{|c|}{$\begin{array}{c}\text { Zero-Order } \\
\text { Correlation Coefficients }\end{array}$} \\
\hline & & & & & 1 & 2 & 3 & 4 \\
\hline $\begin{array}{l}\text { 1. Effectiveness } \\
\text { 2. Strategy } \\
\text { 3. Years in marketing/sales } \\
\text { 4. Willingness to take risk } \\
\text { 5. Tolerance for ambiguity }\end{array}$ & $\begin{array}{r}1.463 \\
-1.000 \\
.000 \\
1.000 \\
1.500\end{array}$ & $\begin{array}{r}4.800 \\
1.000 \\
11.000 \\
9.000 \\
4.000\end{array}$ & $\begin{array}{l}3.205 \\
-.033 \\
5.690 \\
4.000 \\
3.018\end{array}$ & $\begin{array}{r}.739 \\
.513 \\
4.520 \\
1.760 \\
.453\end{array}$ & $\begin{array}{r}.13 \\
.02 \\
-.03 \\
.02\end{array}$ & $\begin{array}{r}-.10 \\
.25^{*} \\
.22^{*}\end{array}$ & $\begin{array}{l}.10 \\
.22^{*}\end{array}$ & $.27^{*}$ \\
\hline
\end{tabular}

*one-tail $p<.05$

This strategy index ranged from -1.00 to +1.00 with a mean value of -.033 . Other summary statistics (as also the matrix of zero-order correlation coefficients among all variables under study) are given in Table 1.

The construct validity of this strategy index was assessed in two ways. First, each respondent was asked to provide data on the current market share of the SBU's principal products, a "factual" rather than "perceptual" item of information. As anticipated, the strategy index correlates negatively with current market share (Pearson $r=-.23$, one-tail $p<.05$ ). In addition, each respondent also was asked to rate each of 12 performance dimensions on a 5-point Likert type scale (ranging from "of little importance" to "extremely important"), indicating the degree of importance attached by superiors to the SBU's performance on that dimension. Responses on this importance question are consistent with expectations. The strategy index correlates positively with the importance of sales growth $(.57, p<.001)$, market share $(.29, p<.05)$, new product development $(.24, p<.05)$, and market development $(.30, p<.01)$ but negatively with the importance of operating profits $(-.23, p<.05)$.

To test for response consistency (a surrogate for internal reliability), each respondent was asked to indicate whether (s)he expected the market share of the SBU's principal products to decline rapidly $(=1)$, decline slowly $(=2)$, remain at the current level $(=3)$, increase slowly $(=4)$, or increase rapidly $(=5)$. As anticipated, the strategy index correlates positively with expectations of an increase in market share $(r=.49, p<.001)$.

SBU Manager's Experience in Marketing/Sales. As part of a more comprehensive question relating to experience background, each respondent was asked to indicate on a 5-point scale the years of total experience accumulated by him/her in the marketing/sales function. The responses were coded as follows: less than one year $(=0), 1$ to 3 years $(=2), 4$ to 6 years $(=5), 7$ to 9 years $(=8)$, and 10 years or more $(=11)$. Summary statistics on the responses are given in Table 1.

Willingness to Take Risk. Bassler (1972) and Slovic (1972) have demonstrated that risk propensity can vary across significantly dissimilar decision 
contexts. Thus, any attempt to measure attitude to risk as a generalized personality trait appeared conceptually unsound, rendering standard personality scales irrelevant for the purposes here. Bassler had discovered, however, that within broadly similar decision contexts (e.g., monetary gambles), risk propensity was stable. Thus it was concluded that eliciting responses to choice-dilemma situations framed in the widely used Kogan and Wallach (1964) format and involving only SBU-level strategic decision making situations not only would capture well the individual manager's willingness to take risk in the context of his/her job, but it also would be free from the faulty assumption of risk propensity as a generalized personality trait. Two such cases were constructed. The format of each case (available from the authors) was identical to Kogan and Wallach's. The scoring procedure also was identical to Kogan and Wallach's except that reverse scoring was used in order to arrive at a measure in which higher values imply greater willingness to take risk. Responses to the two cases were averaged. The interitem reliability estimate (coefficient $\alpha=.57$ ) is within what Nunnally (1967) has argued as the satisfactory range for exploratory research. For purposes of comparison, it might also be noted that, in their original study, Kogan and Wallach (1964) had obtained interitem reliability estimates of .53 (for males) and .62 (for females). Summary statistics on this variable are given in Table 1.

Tolerance for Ambiguity. Four items from the 7-item instrument developed by Lorsch and Morse (1974) were used to measure the respondents' tolerance for ambiguity. The four items were (1) The most interesting life is to live under rapidly changing conditions; (2) Adventurous and exploratory people go farther in this world than do systematic and orderly people; (3) When planning a vacation, a person should have a schedule to follow if he's really going to enjoy himself; and (4) Doing the same thing in the same places for a long period of time makes for a happy life. For each statement, the respondents were asked to indicate on a 4-point scale whether they definitely agreed $(=1)$, were inclined to agree $(=2)$, were inclined to disagree $(=3)$, or definitely disagreed $(=4)$ with the statement. Items 1 and 2 were reverse scored, and a straight average of the responses to the four statements was used as a measure of tolerance for ambiguity. The interitem reliability estimate on these four items for the sample is: coefficient $\alpha=.57$. Summary statistics on this variable are given in Table 1 .

Effectiveness at Strategy Implementation. The absolute performance of a business entity depends not just on the effectiveness of its internal organization in implementing the chosen strategy, but also on industry characteristics and the choice of strategy itself (Lenz, 1981). Given this study's focus on implementation, it was essential, therefore, that the impact of industry and strategy related factors on performance be controlled. Because managers' a priori expectations of business unit performance are likely to take into account the anticipated impact of industry and strategy related 
factors, this requirement suggested that "effectiveness at strategy implementation" be measured in the form of a comparison between actual performance and a priori expectations rather than on an absolute scale. Further, as urged by Steers (1975), it was decided (1) to undertake this comparative performance assessment along a multiplicity of dimensions rather than on any single dimension, and (2) to weight the various performance dimensions in terms of their relative importance for the SBU. Such a multivariate approach with criterion weights was seen as particularly appropriate in a context in which, by definition, different strategic missions imply quite different sets of priorities.

Effectiveness data were collected on 12 performance dimensions: sales growth rate, market share, operating profits, profit to sales ratio, cash flow from operations, return on investment, new product development, market development, R\&D activities, cost reduction programs, personnel development, and political/public affairs. On each of these dimensions, each respondent was asked to rate on a 5-point Likert type scale (ranging from "not at all satisfactory" to "outstanding") the SBU's performance as compared with his/her assessment of superiors' expectations from the SBU on that dimension. Using the data on dimensional importance obtained in an earlier question (see the discussion on construct validity tests for the "strategy" index) as weights, a weighted average effectiveness index was obtained for each SBU. Summary statistics on this variable are given in Table 1. As can be seen, the effectiveness index does not correlate with strategyan indication that the impact of strategy on SBU effectiveness has been adequately controlled. Given the self-report nature of this effectiveness measure, it also is worth noting that, in an earlier study, Heneman (1974) reported a very high correlation between superior and self-ratings in situations in which the subordinate is guaranteed anonymity and understands that the objective of data collection is scientific research and not his/her personal evaluation from the organization's perspective; Heneman's conditions were met fully in this study.

\section{Results}

\section{Tests of Hypotheses}

All three hypotheses tested in this study are of the following form: the positive impact of $X_{1}$ on $Y$ will be stronger when $X_{2}$ is high as compared to when $X_{2}$ is low. Following the arguments of Southwood (1978) and similar to the approaches taken by Argote (1982) and Schoonhoven (1981), the most appropriate analytical method for testing every such hypothesis is to run the two regression equations given below:

$$
\begin{aligned}
& Y=c_{1}+a_{1} X_{1}+a_{2} X_{2}+\epsilon_{1} \\
& Y=c_{2}+b_{1} X_{1}+b_{2} X_{2}+b_{3} X_{1} X_{2}+\epsilon_{2}
\end{aligned}
$$


If the unstandardized regression coefficient $b_{3}$ is positive and significant, one would conclude that the positive impact of $X_{1}$ on $Y$ is indeed stronger for higher as compared to lower values of $X_{2}$. Alternatively, a negative and significant $b_{3}$ would lead to the conclusion that the positive impact of $X_{1}$ on $Y$ is stronger for lower rather than higher values of $X_{2}$. Finally, if $b_{3}$ is not significantly different from zero, one would conclude that $X_{2}$ does not have any contingency effect on the relationship between $X_{1}$ and $Y$. Parenthetically, readers might also note that whenever $b_{3}$ is significantly different from zero, the coefficient of determination $\left(R^{2}\right)$ for equation (2) will be significantly greater than that for equation (1).

Table 2 presents the results from six regression equations-two for each of the three hypotheses. As this table points out, introduction of the crossproduct term increases $R^{2}$ by a significant amount in all three cases. As would be expected, in each case the unstandardized regression coefficient $\left(b_{3}\right)$ of the cross-product term is also significantly different from zero. Finally, in each of the three cases, the sign of the coefficient $b_{3}$ is positive as hypothesized. Thus, the data provide clear and unequivocal support to all three hypotheses.

\section{Tests for the Presence or Absence of Monotonicity}

Although equation (2) is a sufficient test of the hypothesized contingency impact of $X_{2}$ on the relationship between $X_{1}$ and $Y$, in its current form it provides no information on whether the latter relationship is monotonic or nonmonotonic. As demonstrated by Schoonhoven (1981) and Southwood (1978), such information can be obtained by examining the partial derivative of this equation over $X_{1}$. As such, for each of the three managerial characteristics-marketing/sales experience, willingness to take risk, and tolerance for ambiguity-the analysis has been pushed to a second stage in order to yield information on the presence or absence of monotonicity in the impact of the characteristic on SBU effectiveness. Partial derivatives of equations (4), (6), and (8) from Table 2 yield the following:

$\partial($ Effectiveness $) / \partial(\mathrm{Mktg} /$ Sales Experience $)=.005+.155 \times$ Strategy

$\partial($ Effectiveness $) / \partial$ (Willingness to Take Risk) $=-.054+.237 \times$ Strategy

$$
\partial(\text { Effectiveness }) / \partial(\text { Tolerance for Ambiguity })=.082+1.142 \times \text { Strategy }
$$

As can be calculated, $\partial$ (Effectiveness) $/ \partial(\mathrm{Mktg} /$ Sales Experience) is negative for $-1 \leq$ Strategy $<-.03$ and positive for $-.03<$ Strategy $\leq 1$; $\partial$ (Effectiveness) $/ \partial$ (Willingness to Take Risk) is negative for $-1 \leq$ Strategy $<.23$ and positive for $.23<$ Strategy $\leq 1$; and $\partial$ (Effectiveness) $/ \partial$ (Tolerance for Ambiguity) is negative for $-1 \leq$ Strategy $<-.07$ and positive for $-.07<$ Strategy $\leq 1$. Thus, in each of the three cases, the impact of the particular managerial characteristic on effectiveness is nonmonotonic, with the inflection point of the slope falling very close to Strategy $=0$. The following general 
Table

Results of Multiple Regression Strategy Implementation"

$(N=$.

\begin{tabular}{|c|c|c|c|c|c|c|}
\hline \multirow{3}{*}{$\begin{array}{c}\text { Variable Under } \\
\text { Consideration }\left(X_{1}\right)\end{array}$} & \multicolumn{6}{|c|}{ Main Effects Only (Strategy and $X_{1}$ ) } \\
\hline & \multirow{2}{*}{$\begin{array}{l}\text { Equation } \\
\text { Number }\end{array}$} & \multicolumn{3}{|c|}{$\begin{array}{c}\text { Unstandardized Regression } \\
\text { Coefficients } \\
\text { (Standard Errors) }\end{array}$} & \multirow{2}{*}{$\begin{array}{c}F-\text { Ratio } \\
(D F=2,55)\end{array}$} & \multirow[b]{2}{*}{$R^{2}$} \\
\hline & & Constant & $X_{I}$ & $\overline{\text { Strategy }}$ & & \\
\hline $\begin{array}{l}\text { Years of experience } \\
\text { in marketing/sales }\end{array}$ & (3) & 3.189 & $\begin{array}{l}.001 \\
(.022)\end{array}$ & $\begin{array}{l}.120 \\
(.202)\end{array}$ & .18 & .007 \\
\hline $\begin{array}{l}\text { Willingness to take } \\
\text { risk }\end{array}$ & (5) & 3.258 & $\begin{array}{l}-.016 \\
(.059)\end{array}$ & $\begin{array}{l}.135 \\
(.209)\end{array}$ & .21 & .008 \\
\hline $\begin{array}{l}\text { Tolerance for } \\
\text { ambiguity }\end{array}$ & (7) & 3.195 & $\begin{array}{l}-.000 \\
(.226)\end{array}$ & $\begin{array}{l}.119 \\
(.205)\end{array}$ & .18 & .007 \\
\hline
\end{tabular}

${ }^{a}$ All of the results (including the significance levels) given in these two columns vary with changes in the points of origin of the two main variables ( $X_{1}$ and strategy). Hence, all information in these two columns should be regarded as essentially meaningless. For details, see Southwood (1978).

bor the cross-product term, the values of the unstandardized regression coefficient, its standard error, and its level of significance are independent of the points of origin of the two main variables ( $X_{1}$ and strategy). Hence, the data in this column do have information content.

cThe $F$-ratio and $R^{2}$ for the equation are independent of the points of origin of the variables $X_{1}$ and strategy.

${ }^{*} p<.05$

* $p<.01$

For $t$-tests, these are two-tail significance levels.

conclusion now can be drawn from equations (9) through (11): Greater marketing/sales experience, greater willingness to take risk, and greater tolerance for ambiguity contribute to effectiveness in the case of build SBUs but hamper it in the case of harvest SBUs.

\section{On-the-Job Personality Development vs. Prior Selection}

The above findings lead one to expect that build SBUs should, in general, have GMs with greater marketing/sales experience, greater willingness to take risk, and greater tolerance for ambiguity than would harvest SBUs. As Table 1 points out, such an expectation is borne out at least for the two personality characteristics-willingness to take risk and tolerance for ambiguity.

An important question that deserves some further analysis is the extent to which this positive association between strategy and willingness to take risk, as well as that between strategy and tolerance for ambiguity, is due to on-the-job personality development rather than a priori selection. Depending on the answer, the normative implications for corporate level executives would be quite different: If on-the-job experience at managing a build or a harvest strategy has a major impact on the individual GM's willingness to take risk and tolerance for ambiguity, then a priori matching of managers and SBU strategy would not be very critical; otherwise, it would be. The study does shed at least some light on this issue. 


\section{2}

Analyses with "Effectiveness at as the Dependent Variable 58 SBUs)

\begin{tabular}{|c|c|c|c|c|c|c|c|}
\hline \multicolumn{7}{|c|}{ Main and Interaction Effects (Strategy, $X_{1}$, Cross-Product) } & \multirow{3}{*}{$\begin{array}{c}\text { F-Ratio of } \\
\text { Increment } \\
\text { in } R^{2} \text { Due to } \\
\text { Inclusion of } \\
\text { Cross- } \\
\text { Product Term } \\
(D F=1,54)\end{array}$} \\
\hline \multirow[b]{2}{*}{$\begin{array}{l}\text { Equation } \\
\text { Number }\end{array}$} & \multicolumn{4}{|c|}{$\begin{array}{c}\text { Unstandardized Regression } \\
\text { Coefficients } \\
\text { (Standard Errors) }\end{array}$} & \multirow{2}{*}{$\begin{array}{c}F-\text { Ratio }^{\mathrm{c}} \\
(D F=3,54)\end{array}$} & \multirow[b]{2}{*}{$R^{2 \mathrm{c}}$} & \\
\hline & Constant & $X_{1}^{\mathrm{a}}$ & Strategy ${ }^{\mathrm{a}}$ & $\begin{array}{l}\text { Cross- } \\
\text { Product }^{\mathrm{b}}\end{array}$ & & & \\
\hline (4) & 3.211 & $\begin{array}{l}.005 \\
(.021)\end{array}$ & $\begin{array}{l}-.865^{*} \\
(.345)\end{array}$ & $\begin{array}{l}.155^{* * *} \\
(.046)\end{array}$ & $3.95^{*}$ & .186 & $11.87^{* *}$ \\
\hline (6) & 3.351 & $\begin{array}{l}.0211 \\
-.054 \\
(.059)\end{array}$ & $\begin{array}{l}-.809 \\
(.455)\end{array}$ & $.237^{*}$ & 1.94 & .101 & $5.59^{*}$ \\
\hline (8) & 2.878 & $\begin{array}{l}.082 \\
(.212)\end{array}$ & $\begin{array}{l}-3.522 * * \\
(1.213)\end{array}$ & $\begin{array}{l}1.142^{* *} \\
(.376)\end{array}$ & $3.21^{*}$ & .156 & $9.53^{* *}$ \\
\hline
\end{tabular}

As part of the study, data also were collected on the number of years spent by each respondent on his/her current job. If willingness to take risk and tolerance for ambiguity were the result largely of on-the-job personality development, then tenure on the job would be expected to make a greater positive contribution to these two personality characteristics in the case of build as opposed to harvest SBUs. Statistical tests (similar in form to those carried out earlier for testing the three main hypotheses) indicate that interaction between tenure on the job and strategy has no significant impact on either willingness to take risk or tolerance for ambiguity. These results do not negate the possibility of on-the-job personality development prior to becoming a GM, but they do support the notion that by the time individuals reach GM positions, their risk propensity and tolerance for ambiguity have more or less stabilized. Thus, the advocates of an a priori matching of GMs to SBU strategy seem to be on essentially the right track.

\section{Discussion}

In recent years, several practitioners/consultants ("The right manager," 1981; “Wanted: A manager," 1980; Wissema, et al., 1980; Wright, 1974) as well as academic researchers (Hofer \& Schendel, 1978; Kerr, 1982; Tichy, Fombrun, \& Devanna, 1982) have argued for the need to match the characteristics of the business unit's general manager to either its strategic mission or its stage in the product life cycle. The study presented in this paper 
has provided clear empirical support to these normative expectations along at least a few key dimensions. Its results can be summarized as follows: Greater marketing/sales experience, greater willingness to take risk, and greater tolerance for ambiguity contribute to effectiveness in the case of build SBUs but hamper it in the case of harvest SBUs.

At the level of practice, these findings hold the greatest relevance for those executives responsible for the selection, development, and appointment of middle level GMs in diversified corporations. On the other hand, at the level of theory, the primary relevance of this study lies in its extension of the contingency theory of organization from the interfirm to the intrafirm context. Thus, future contingency research on a variety of SBU level strategic and organizational variables (including but not limited to managerial characteristics) not examined in this study can be expected to yield fruitful results. The design of future research in this area also might benefit from the following examination of the key limitations in the present study.

An obvious limitation of this study has been its exclusive reliance on selfreport measures particularly for the two key variables-"strategy" and "effectiveness at strategy implementation." The authors believe that the results of validity and reliability tests carried out and discussed earlier argue for sufficient confidence in these measures, but that a similar study with multimethod, multirater measurements should yield more powerful results.

A second limitation of this study has to do with the establishment of causality. Although all hypotheses are stated in associational terms, the logic behind them implies that interaction between strategy and managerial characteristics is not just associated with but causes greater effectiveness. The cross-sectional and snapshot nature of the data prevented any tests for such causality. Unlike the first limitation, however, given constraints of time and resources, future researchers are likely to find this limitation much more difficult to overcome. Causality manifests itself over time and individuals' personalities are liable to change; thus, data would have to be collected longitudinally and concurrently over long periods of time rather than retroactively. Thus, the methodologies adopted by Chandler (1962), Mintzberg and Waters (1982), or Rumelt (1974) are not likely to be of much help. As a practical matter, therefore, perhaps the greatest promise for the establishment of causality might lie not in field studies but in well designed laboratory simulations patterned after Miles and Randolph (1980).

Arguably the most significant limitation of this study has been its focus on only a few variables pertaining to both strategy and managerial characteristics. Strategies of SBUs within diversified firms differ not just in terms of the strategic mission, but also in terms of the competitive posture relative to other firms in their respective industries (Porter, 1980). It is not inconceivable that an SBU trying to achieve a low cost position might require different managerial characteristics as compared to an SBU whose primary concern is the upgrading of product features/performance rather than cost reduction. Other dimensions along which SBU strategies can be 
differentiated also exist-for instance, the degree of "interconnectedness" between the focus SBU and other SBUs within the same corporation (Rumelt, 1974). Similarly, marketing/sales experience, risk attitude, and tolerance for ambiguity are only a few of the pertinent and important dimensions along which characteristics of SBU general managers might or might not systematically differ in line with SBU strategy. At least some of the more important dimensions worthy of investigation might be: other dimensions of experience, background, age, interpersonal versus task orientation, attitude towards authority, and leadership style. Well-established instruments for measuring virtually all of these managerial characteristics already exist.

Finally, it is worth noting that the focus of the present study, as well as of virtually all previous literature dealing with linkages between strategy and managerial characteristics, has been on the implications of matching strategy and managerial characteristics for only an "organizational" outcome, namely, effectiveness. Given the normally high degree of interaction between personal and organizational outcomes, research on the implications of matching strategy and managerial characteristics for managerial job involvement and job satisfaction would seem to be of at least equal significance.

\section{References}

Abell, D. F., \& Hammond, J. S. Strategic market planning. Englewood Cliffs, N.J.: Prentice-Hall, 1979.

Andrews, K. R. The concept of corporate strategy. Homewood, Ill.: Dow-Jones-Irwin, 1971.

Ansoff, H. I. Corporate strategy. New York: McGraw-Hill, 1965.

Argote, L. Input uncertainty and organizational coordination in hospital emergency units. Administrative Science Quarterly, 1982, 27, 420-434.

Bassler, J. F. The consistency of risk attitudes in decision-making under uncertainty. Unpublished doctoral dissertation. Graduate School of Industrial Administration, Carnegie-Mellon University, 1972.

Bower, J. L. Managing the resource allocation process. Boston, Mass.: Division of Research, Graduate School of Business Administration, Harvard University, 1970.

Buzzell, R. D., \& Wiersema, F. D. Modelling changes in market share: A cross-sectional analysis. Strategic Management Journal, 1981, 2, 27-42.

Chandler, A. D. Strategy and structure. Cambridge, Mass.: The M.I.T. Press, 1962.

Child, J. Organization structure, environment, and performance: The role of strategic choice. Sociology, $1972,6,1-22$.

Fiedler, F. E. Engineer the job to fit the manager. Harvard Business Review, 1965, 43(5), 115-122.

Fouraker, L. E., \& Stopford, J. M. Organization structure and multinational strategy. Administrative Science Quarterly, 1968, 13, 57-70.

Galbraith, J. R., \& Nathanson, D. A. Strategy implementation: The role of structure and process. St. Paul, Minn.: West, 1978.

Griffin, R. W. Relationship among individual, task design, and leader behavior variables. Academy of Management Journal, 1980, 23, 665-683.

Grinyer, P., Al-Bazzaz, S., \& Yasai-Ardekani, M. Strategy, structure, the environment, and financial performance in 48 United Kingdom companies. Academy of Management Journal, 1980, 23, 193-220.

Hambrick, D. C. Operationalizing the concept of business-level strategy in research. Academy of Management Review, 1980, 5, 567-575. 
Henderson, B. D. Perspectives on the product portfolio. Boston, Mass.: Boston Consulting Group, 1970.

Heneman, H. G., III. Comparisons of self and superior ratings of managerial performance. Journal of Applied Psychology, 1974, 59, 638-642.

Hitt, M. A., Ireland, R. D., \& Palia, K. A. Industrial firms' grand strategy and functional importance: Moderating effects of technology and uncertainty. Academy of Management Journal, 1982, 25, 265-298.

Hofer, C. W., \& Schendel, D. E. Strategy formulation: Analytical concepts. St. Paul, Minn.: West, 1978.

Kerr, J. Assigning managers on the basis of life cycle. The Journal of Business Strategy, Spring 1982, 58-65.

Knight, F. H. Risk, uncertainty, and profit. New York: Houghton Mifflin, 1921.

Kogan, N., \& Wallach, M. A. Risk taking: A study in cognition and personality. New York: Holt, Rinehart, and Winston, 1964.

Larreche, J., \& Srinivasan, V. Stratport: A model for the evaluation and formulation of business portfolio strategies. Management Science, 1982, 28, 979-1001.

Lawler, E. E., III. For a more effective organization-Match the job to the man. Organizational Dynamics, 1974, 3(1), 19-29.

Lawrence, P. R., \& Lorsch, J. W. Organization and environment. Boston, Mass.: Division of Research, Graduate School of Business Administration, Harvard University, 1967.

Lenz, R. T. "Determinants" of organizational performance: An interdisciplinary review. Strategic Management Journal, 1981, 2, 131-154.

Lorsch, J. W., \& Allen, S. A., III. Managing diversity and interdependence. Boston, Mass.: Division of Research, Graduate School of Business Administration, Harvard University, 1973.

Lorsch, J. W., \& Morse, J. J. Organizations and their members: A contingency approach. New York: Harper \& Row, 1974.

Luce, D., \& Raiffa, H. Games and decisions. New York: Wiley, 1957.

MacMillan, I. C. Seizing competitive initiative. The Journal of Business Strategy, Spring 1982, 43-57.

Miles, R. E., \& Snow, C. C. Organizational strategy, structure, and process. New York: McGrawHill, 1978.

Miles, R. H., \& Randolph, W. A. Influence of organizational learning styles on early development. In J. R. Kimberly, R. H. Miles, \& Associates (Eds.), The organizational life cycle. San Francisco: Jossey-Bass, 1980, 44-82.

Mintzberg, H., \& Waters, J. A. Tracking strategy in an entrepreneurial firm. Academy of Management Journal, 1982, 25, 465-499.

Nunnally, J. C. Psychometric theory. New York: McGraw-Hill, 1967.

O'Reilly, C. A. Personality-job fit: Implications for individual attitudes and performance. Organizational Behavior and Human Performance, 1977, 18, 36-46.

Pfeffer, J., \& Salancik, G. R. The external control of organizations. New York: Harper \& Row, 1978.

Porter, M. E. Competitive strategy. New York: Free Press, 1980.

The right manager for the strategic mission. Cambridge, Mass.: The Strategic Planning Institute, 1981.

Rothschild, W. E. Putting it all together: $A$ guide to strategic thinking. New York: AMACOM, 1976.

Rumelt, R. P. Strategy, structure, and economic performance. Boston, Mass.: Division of Research, Graduate School of Business Administration, Harvard University, 1974.

Schoonhoven, C. B. Problems with contingency theory: Testing assumptions hidden within the language of contingency "theory." Administrative Science Quarterly, 1981, 26, 349-377.

Scott, B. R. The industrial state: Old myths and new realities. Harvard Business Review, 1973, 51(2), 133-148.

Slovic, P. Information processing, situation specificity, and the generality of risk-taking behavior. Journal of Personality and Social Psychology, 1972, 22, 128-134. 
Snow, C. C., \& Hrebiniak, L. G. Strategy, distinctive competence, and organizational performance. Administrative Science Quarterly, 1980, 25, 307-335.

Southwood, K. E. Substantive theory and statistical interaction: Five models. American Journal of Sociology, 1978, 83, 1154-1203.

Steers, R. M. Problems in the measurement of organizational effectiveness. Administrative Science Quarterly, 1975, 20, 546-558.

Thompson, J. D. Organizations in action. New York: McGraw-Hill, 1967.

Tichy, N. M., Fombrun, C. J., \& Devanna, M. A. Strategic human resource management. Sloan Management Review, 1982, 23(2), 47-61.

Vancil, R. F. Decentralization: Managerial ambiguity by design. New York: Financial Executives Research Foundation, 1980.

Wanted: A manager to fit each strategy. Business Week, February 25, 1980, pp. 166-173.

Wissema, J. G., Van Der Pol, H. W., \& Messer, H. M. Strategic management archetypes. Strategic Management Journal, 1980, 1, 37-47.

Wright, R. V. L. A system for managing diversity. Cambridge, Mass.: Arthur D. Little, 1974.

Anil K. Gupta is Assistant Professor of Management Policy at the School of Management, Boston University.

V. Govindarajan is Assistant Professor of Accounting at the College of Administrative Science, Ohio State University. 
Copyright of Academy of Management Journal is the property of Academy of Management and its content may not be copied or emailed to multiple sites or posted to a listserv without the copyright holder's express written permission. However, users may print, download, or email articles for individual use. 